\title{
Exploring the Elderly Care from the Community of Factory Section Type in China
}

\author{
Xu CHEN \\ PhD. candidate, School of Humanity and Social Science, Harbin Institute of Technology, China \\ Email: Donghae0101@126.com
}

Keywords: Elderly care, Community of Factory Section Type, Care-giving model.

\begin{abstract}
Since the sharp increase in aging population is being whole nationwide in China, the government are being trying to promote new and efficient elderly care-giving models to satisfy various situations and needs, while they are still obliged to face up such a lot tough challenges when conducting. Community of Factory Section Type stands for a very special kind of community. As a production of planned economy, they are left over some particular features and problems by the old government-business relationship. In this research, we argue that Communities of Factory Section Type have some strong advantages in some main aspects of elderly care (like day care programs, health and wellness services, and the recreational activities, as well as inner comfort for the elder residents), which is the most real problem of elderly care.
\end{abstract}

\section{Background}

According to State Council of Peoples Republic of China 2006, aging people(60+) comprised approximate 11 percent(114 million) of China's total population(1.3 billion) in 2005. What's more, it is estimated to go up to 25 percent in 2050[1]. This sharp increase in aging population is being whole nationwide. And even the worse, it occurred much more rapidly in China's worst economically disadvantaged rural areas, and number is almost approaching to 60 percent(China National Committee on Aging, 2006). Although many policies targeted to elderly care have been establishing since 1982, China still need face up to such a lot tough challenges when conducting.

The political, social, and economic changes that took place in China since economic reforms began in the 1980s have weakened the traditional family care practices[2]. Millions of people went to large cities or other places to work as the result of widespread market economy, thus making the original family structure fractured and damaged. In addition, China's family planning policy(The One Child Policy) initiated in 1971 has strained traditional extended family care-giving networks that had enabled older people to remain with their families in their homes[3]. While extended family members living under one roof remains the norm today, this arrangement is declining, as the average household size has steadily decreased since 1980s from 44 members in 1982 to 3.13 in 2005(National Bureau of Statistics of the People's Republic of China, 1987, 2006). Consequently, the number of empty nest households(older parents living by themselves has a tremendous growth. For example, in Zhejiang province, about 37 percent of older people lived by themselves(National Bureau of Statistics of People's Republic of China, 2013). Elderly care problem, which is becoming serious day after day, making it a major challenge for both Chinese government and the society in the upcoming years.

Traditional care of older people in China is rooted in Confucianism, whereby parental devotion(filial piety) and ancestor worship, and care for older family members has been a normative family duty[4,5]. Care of elders has traditionally been provided at home by spouses, children, in-laws(particularly daughters in-law) and extended family members. The Chinese proverb, 'Having a son makes one's old age secure', effectively describes China's expectation and obligation to Chinese parents[2]. Due to these traditional home-care perspectives, most families are choosing nursing home other than institutional care. Even the government has written it into laws and policies. The P.R.China Elderly Rights and Protection Law(1996), for instance, demands that older people should be respected and taken care by the family members. 


\section{Three Types of Elderly-care Model in China}

As the traditional elderly care-giving model is strongly shocked by the changing family structures, Chinese government attempts to fill the gap by promoting institutional care for older people. With various approaches to mobilize social resources, especially for capital investment, care institutions started booming from cities to towns, known as two types of management, state-built institutions and privately managed institutions. But later the quantities of the two types of institutions appeared an extreme imbalance, for example, Heilongjiang province had only 37 government-run institutions before 2014, while the number of privately managed institutions had already gone to 987, almost 96 percent of the total. Despite the sharp increase in elderly care institutions, the proportion of elder people in them remains small compared to the number who need it[2]. Approximately 12 percent of China's older people reported preferring to live in an elder institution. However, only 0.8 percent of older people are able to do so[6,7]. Family financial constraints, concerns over the quality of care provided by institutions are the main factors for this discrepancy.

Since 1990s, Chinese government has been prompting a new social service program, known as Community-based in-home care, which is considered have neutralized both the advantages of family and institutional care. It is believed suits China's rapidly aging population and respects its cultural traditions. Clearly, the lack of adequate affordable elder care institutions and the weakened traditional family care-giving system have made community-based in-home care an appealing option[8]. Community-based in-home care advocates elder people live at home, and the communities where they live in are the places providing care and services delivery. It is a strong step to cover the needs especially for those older people whose children live or work in distant. What's more, China's community-based in-home care is designed in wide range of service programs which oriented by communities, such as home visits, emergency aids, day care programs, health and wellness clinics, and the recreational activities that could benefit over 30 million older people(State Council of the Peoples Republic of China, 2006). Meanwhile, this care program is designed for elder people in various situations and needs. For example, the very old(age 80+), people with disabilities and chronic diseases, those living alone without adult children or family members nearby, to name a few (Ministry of Civil Affairs of the People's Republic of China, 2006). Today, community-based services in China include both government-funded public, welfare assistance(such as low-income family benefits), and community-oriented, self-help initiatives(such as day care programs and community kitchens).

\section{Origins of Community of Factory Section Type}

Community of Factory Section Type stands for a very special kind of community. As a production of planned economy, they are left over some particular features and problems by the old government-business relationship.

Since China was found in 1949, many state-owned enterprises(SOEs) had been established especially in Northeast, aiming to achieve a boost in heavy industry and modernization. At that age, besides basic welfare and salaries, these SOEs had to provide all kinds of living facilities, known as employee benefits, such as houses, schools, stores, hospitals, dining halls and even cinemas. All of these facilities and services, named as Corporate Social Functions, offered great convenience to the resident living in the communities which almost covered every aspects of life, and just cost very little. People didn't need to go father to supply or entertain themselves, because most of their needs would be met in the communities, thus making these communities like one by one separately tiny societies. And a constitute called neighborhood committee was specially launched to support residents' daily life, notably the welfare of the retired and the newborns. What's more, with the permission of inheriting one's parent's occupation, even the employment issue was solved that successfully. The dominant view on Corporate Social Functions is quite positive and never denies their clear benefits, and there is no doubt that Corporate Social Functions did play a crucial role in early national economy, because all the policies and services showed great advantages to form a steady working state for the employees, so as to enhance their working efficiency and motivation. 
Obviously, working in SOEs definitely was taken as a good occupation at that time, but unfortunately, nothing good last long.

Stepping into 1980s, SOEs faced increasingly competitive pressures with the declining of planned economy. Capacity utilization in more than half of all industrial SOEs was below 60\%. Then, series of reforms initiatives were launched to operate on a more market-oriented basis, free from political intervention in order to reduce wastage, be more efficient and ultimately improve profit. Corporation, when the National People's Congress passed the Enterprise Law in 1993, allowing for the setting up of an independent legal entity, with the state as owner, able to act in a commercial way, while governed by public laws like a private enterprise. During these series of reforms, thousands of SOEs were merged, leased out, bankrupted, or even sold, and about one-third of all employees laid off from industrial SOEs[9]. This reform later indirectly led to the emergence of Communities of Factory Section Type. Since all staff residence were provided by SOEs, those districts whose residents afflicted to SOEs usually refer to a large scale of neatly arranged old buildings with lots of people living there. In addition, most laid off workers lost their jobs at the age of 40 s or 50 s with barely possibility of moving out, gradually turning to elderly people as getting old.

After Community Construction was raised in 2000, communities were requested to shift to resident self-government model, and developed in much comprehensive ways. Many neighborhood committees were directly turned into Communities, because they were granted some privileges to assistance residents' daily life under the support of government before, and they were familiar with the residents living there.

\section{Features of Community of Factory Section Type}

Generally speaking, Communities of Factory Section Type share the similarities on the area as well as economic circumstances. First, they usually locate at the edges of cities and remote of downtown, as the result of industrial location elements. This type of communities are always not that new and modern. Old and low buildings, narrow and crowded streets, with small internal rooms and plain designs. While they still possessing obvious advantages on account for various of living accommodation, like schools, hospitals, shops, and other entertainments.

Then comes with the features of demography. Communities of Factory Section Type are basically known as large-scale residence with large quantities of residents. For example, Harbin The First Machinery Works(HFMW), the community where we conducted our research, used to be a neighborhood committee in a SOE. With the floor space of 0.49 square kilometer, 6338 households and 85 buildings, HFMW Community is no doubting an ultra-large community with over 18000 residents. Among them, most are the laid off workers and their families. In 1997, HFMW went broke, leaving little allowance to over 8000 laid off workers. Even though some people among them lived a better life by starting a new career or getting support from their children, most of those laid off workers suffered from poverty for a long period. In most of the cases, those former residents whose living conditions later have been improved always moving out, thus leaving the rest with poor financial circumstances. What gives them much more depress is, they can't stop to step into ageing, and the elderly people(60+) increased sharply to more than 3000 within 20 years after the factory was closed.

\section{Findings from Interview Survey}

Even though China's real estate market began to boost after the year of 2000, and people are always failing to distract their eyes from new-styled commercial flats in modern communities with well-designed surroundings and fewer residents to live in. However, most of these modern communities in China can't afford the service for the residents' every aspect of their life in consideration of many reasons, especially the capital cost of construction. The SOEs established many living facilities and recreational places for their employees in the early time, some of them remained after the SOEs went broke. These facilities and recreational places could be viewed as the 
only gifts left by their former factories, and bring those old residents convenience and benefit as before. Thus, the first advantage of communities of Factory Section Type is, there are many existing places and playing fields to support various elderly care services, relieving the pressure of a huge cost on construction, like hospitals or clinics, daily-care rooms, and recreational places.

"Our community is very old, as you can see”, said by Mr. Li(aged 65), a retired worker from HFMW, "But we don't feel that incontinent. Stores and shops are scattered around, and if we feel sick, we turn to the hospital(which belonged to HFMW). There is a gym just in the corner of our community, and you see that red building with yellow roof? Inside it there are various rooms for recreational activities, like singing and dancing, handwriting, painting, etc.

Convenience, which does matter a lot as to the life of elderly people, keeps their pace slowing down so as to take care of the age. "As we are getting old, it's better to live in an comparatively convenient place, thus we don't need to go far to shopping, see a doctor, and entertain myself." Went on by Mr. Li, "Especially the hospital, that's too much important for us old people. Though I'm now living in our old community, some of my former neighbors cannot help envying me even if they were settled in new communities by their children, because it's not as convenient as before to see a doctor in their new communities." Notably, elderly people receive the benefits since the existing of the original facilities and service left by SOEs, moreover, they absolutely offer some essential material support to implement and develop the wide range of service programs in China's community-based in-home care for elderly people, especially on day care programs, health and wellness services, and the recreational activities.

Besides of the benefits of material support, there is another interesting founding coming out during our survey. Although most of the elderly people we interviewed were forced to be laid off by HFMW, we are very surprised to find they all have a deep affection for their old communities. In some cases, the elderly himself/herself rejected to move out even if their families' financial status is pretty good. Apart from the convenient facilities and service, the reason that keeps them couldn't help staying here is the people. Since all the residences in SOEs were built to meet the ends with the staff and their families. It's not strange that your neighbor is also your workmate, and his daughter is a classmates of your daughter. That is to say, most of the residents in the Communities of Factory Section Type are sharing the relatively coincident social networks, and with time passing by, these social networks turn to become stronger since the emergence of irreplaceable mental pleasure they may receive from each other.

"I won't leave this community", said by Mrs. Wang(Aged 73), a retired worker of HFMW, “All my friends are here, and I'm accustomed to living here everywhere. I don't think that's bad option, because I feel happy myself.” Another case comes from Mrs Lu(Aged 68), giving us some other inspires on social relationship and mental health. "Sometimes when I need someone to share my feeling, no matter good or bad, I'll go to my neighbor Mrs. Wu, who is also my old workmate and friend. She is also glad to share me everything. As long as we stay together chatting the trifles, both of us are feeling good, and all the awful things are gone." Owing to these interactions and communities, the residents found a good way to express and exchange their emotions, which is very beneficial to their mental and psychological health. In other words, elderly people get fulfilled and entertained by living in such conversant circumstances, communicating timely when they need someone to talk with, and engaged in sufficient and dense social network, thus avoiding from feeling lonely and isolated.

According to the policies of China's community-based in-home care, mental health is expected to be put high premium nowadays since more and more elderly people are self-reported to suffer mental disorders as a result of multiple reasons, like empty nested and the sense of ageing crisis, which leaving them unspeakable to feel down and lonely. "People 65 and over had more than two and a half times the rate of self-reported mental disorders(12.3\% of 65 and over, compared with 4.5 percent of people from 15 to 64), and that older women reported mental disorders at almost twice the rate of older men[10]. Enjoy a fulfilling and rewarding life is key to avoiding depression in any age, as is being socially and physically active, living in a supportive community, and having access to friends, family, and neighbors. Since China's community-based in-home care demands that 
communities are ought to provide various mental care service to meet the end of the old people's mental health, the communities are trying to launch series of events to cooperate, such as regular talks, psychological comfort, and some activities to pleasure their moods and feelings, whereas HFMW doesn't need to put too much human and material circumvention into special service for mental care, because most of the residents are initiative to go out of their home and take various kinds of activities both in and out community with their friends. "Our residents are very passionate for the events and activities, as well as the interest groups", said by the director of HFMW residential committee, Mrs Wang(Aged 73), who is also a retired worker from HFMW, "Old as it is, our community is full of what those new communities are insufficient, and it can't be replaced by those tall and nice buildings as well as fine and amazing designs. We are united in every aspect of life, for such a long time, deeply penetrating in soul, that's why you got the strong sense of affection when you walking in HFMW.

\section{Conclusion}

Since China's community-based in-home care for elderly people is community oriented, community plays the most significant role in service delivery and organizations. According to China's Urban Resident Community Organizing Law(1989) and the Rural Villagers' Committee Organizing Law(1998), the communities have the responsibilities to provide welfare services for residents which are established by the government with its financial support and aimed to meet the multiple needs of residents in the community, based on street, township and the Resident Committees that organize and provide services by mobilizing various community resources.(Ministry of Civil Affairs of the P.R.China, 1995) Compared with other type of communities, these Communities of Factory Section Type share some unique characteristics which makes big difference when approaching the elderly-care policies. In this research, we were surprised to discover that Communities of Factory Section Type have some strong advantages in some main aspects of elderly care (like day care programs, health and wellness services, and the recreational activities, as well as inner comfort for the elder residents, which is the most real problem of elderly care.

\section{Reference}

[1] Chen, W. China’s Population Trend: 2005-2050, J. Population Studies(China) 2006, (4):93-95.

[2] Qingwen Xu and Julian C.Chow Exploring the Community-based Service Delivery Model: Elderly Care in China, J. International Social Work 2001, 54(3):374-387.

[3] Poston, D. And C.C. Duan The Myth of Social Support and Integration in I. Chi, N. L. Chappell and J. Lubben(eds) Elderly Chinese and Elder care in the People's Republic of China, J. Journal of Family Issues 2000, 21(6): 714-732.

[4] Wu, B., M.W. Carter, R.T. Goins and C. Cheng Emerging Services for Community-based Long-term Care in Urban China: A Systematic Analysis of Shanghai's Community-based Agencies, J. Journal of Aging \& Social Policy 2005, 17(4): 37-60.

[5] Zhan, H.J. and R.J.V. Montgomery Gender and Elder Care in China: The Influence of Filial Piety and Constructional Constraints, J. Gender \& Society 2003, 17(2):209-229.

[6] Dong, L. China's Social Security System: Challenges and Response, information on China Business. Retrieved 4 June 2009 from http://www.cnca.org.cn/default/iroot1000610000/4028e47d208847f601208890480a0037.html.

[7] He, X. Community Elderly Care: Moving Forward, J. China Elderly (China) 2001, (4): 8-15.

[8] Derleth, J. and D.R. Koldyk The Community Experiment: Grassroots Political Reform in Urban China, J. Journal of Contemporary China 2004, 13(41): 747-777.

[9] Carsten A. Holz China’s industrial state-owned enterprises: between profitability and bankruptcy. 
Singapore: River Edge, N. J., 2003.

[10] J.A. Auger and Diane Tedford-Litle From the Inside Looking Out: Competing Ideas About Growing Old. Canada: Fernwood Publishing Co., Ltd, 2004.

China National Committee on Aging (2006) China’s Aging Population Trend Forecasting Study. Beijing: China National Committee on Ageing.

Ministry of Civil Affairs of the People's Republic of China (1995) National Criteria of Community Services. Beijing: Ministry of Civil Affairs of the People's Republic of China.

Ministry of Civil Affairs of the People's Republic of China (2007) 2006 Civil Affairs Development Statistics. Beijing: Ministry of Civil Affairs of the People's Republic of China.

State Council of the People's Republic of China (2006) White Paper on the Development of the China National Committee on Ageing. Beijing, China: State Council of the People's Republic of China. 